\title{
Collision Induced Dissociation-Based Characterization of Nucleotide Peptides: Fragmentation Patterns of Microcin C7-C51, an Antimicrobial Peptide Produced by Escherichia coli
}

\author{
Vanessa W. Petit, ${ }^{\text {a }}$ Séverine Zirah, ${ }^{\text {a Sylvie Rebuffat, }}{ }^{\text {a }}$ \\ and Jean-Claude Tabet ${ }^{\mathrm{b}}$ \\ ${ }^{a}$ Muséum national d'Histoire naturelle, Laboratoire de Chimie et Biochimie des Substances Naturelles, Paris, \\ France \\ ${ }^{\mathrm{b}}$ Université Pierre et Marie Curie (Paris VI), Laboratoire de Chimie Structurale Organique et Biologique, \\ Synthèse, Structure et Fonction de Molécules Bioactives, Paris, France
}

Covalent@rotein-nucleic@cid@onjugates@orm@n@riginal@lass@f@ompounds@hat@ccur@n nature@r@an@e@enerated@n@itro@hrough@ross-linking@o@nvestigate@lomains@nvolved@n protein/nucleic@cid@interactions. Cheir@nass@pectrometry@ragmentation@atterns@reథoorly characterized.\$e@have@ised@lectrospray-ionization@mass@pectrometry@ESI-MS)@ombined with@ollision-induced@issociation@CID)@o@haracterize@nicrocin@7-C51,@an@intimicrobial nucleotide@eptide@hat@argets@spartyl-tRNA@ynthetase@nd@nhibits@ranslation.đThe@ragments@f@nicrocin@7-C51@vere@nalyzed@n@ositive-@nd@egative-ion@nodes@nd@ompared with@those@of@the@corresponding@unmodifiedCheptapeptideCand@to@the@derived@aspartyladenylate.CThe@positive-Cand@negative-ion@mode@fragments@of@microcin@C7-C51@provided information@on@both@the@nucleotide@and@peptide@moieties.@Accurate@mass@measurement obtained@ising@nđTQ@rbitrap@nstrument@was@đRey@actor@or@@omprehensive@nterpretation@fథhe@ragments.\$he@xperimental@esults@btained@ermitted@he@roposal@f@tepwise fragmentation@athways@nvolving@on-@ipole@omplexes.CThe@lata@rovide@@etter@inderstanding@f@ucleotide@eptide@ragmentation@n@he@as@hase.C (JCAm@Soc@Mass@spectrom 2008,@9,®187-1198)@(2008@American@Society@or@Mass@Spectrometry

$\mathrm{F}$ undamental@rocesses@f@ene@egulation@y@egulatory@proteins@depend@on@the@recognition@of nucleic@cid@tructures@r@ase@equences.@nteractions@etween@ucleic@cids@ndథpeptides/proteins@an result@n@ovalent@omplexes@hat@ither@ct@s@rchitectural@omponents@f@he@ell,@r@ead@o@p-@r@ownregulation@ofCa@specific@gene@through@activation@1]. Cross-linkedథpeptide@rథrotein-nucleic@cid@onjugates

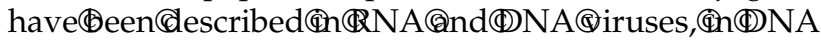
topoisomerases,@r@s@mino@id-RNA@onjugates@n aminoacyl-tRNAs $₫ 2] . \oplus$ urthermore, $₫ V$-induced@rosslinking@has@merged@s@n@fficient@nethod@o@haracterizeबRA@nteractions@ithథeptides/proteins,@nథarticular@ithin@ibonucleoproteinథarticlesథ3, (4].

Electrospray-ionization $(\mathrm{ESI}) @ s @ n @$ @ergetically@oft ionization $\odot$ process $\odot$ and $\odot$ has $\odot$ become $\odot$ the $\odot$ standard method@o@haracterize@@arge@ariety@f@iomolecules. While@much@f@he@arly@ork@oncerns@eptides@nd proteins, $₫$ here@has@een@n@ncreasing@umber@f@tud-

Address reprint requests to Professor Jean-Claude Tabet, Laboratoire de Chimie Structurale Organique et Biologique, Université Pierre et Marie Curie (Paris VI), Bât F, Boîte 45, 4 place Jussieu 75252 Paris Cedex 05, France. E-mail:@abet@ccr.jussieu.fr ies@hat@have@demonstrated@he@xcellent@potential@f ESI-MS@for@the@characterization@of@nucleotides@[5].

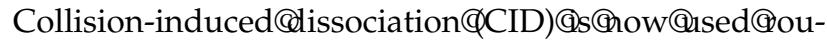
tinely@o@equence $\$$ rotonated $\$$ peptides $\Phi 6] . \oplus$ ragmenta-

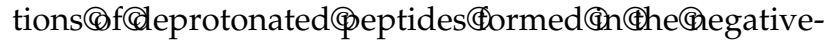
ion $\odot$ mode $\odot$ are $\odot$ currently@less $\odot$ used $\odot$ for@sequencing purposes $₫ 7, \mathbb{C} 8] . \mathbb{C} F u r t h e r m o r e, @ \mathbb{C I D} @ x$ periments Chave allowed@he@haracterization@f@iagnostic@roduct $₫$ ons of甲rotonated@nd@eprotonated@ucleotides@nd@ucleotide@erivatives \$9,®0].đHowever,@he@as-phase@ragmentations@f@ucleotide@peptides@have@merely@een@nvestigated.๑19 electron@onization@ere@hown@o@e@ble@o@somerize into@ion-@ipole@complexes@before@dissociation.@This potential@was@emonstrated@by@Bowen@t@1.@11]@or small@molecules@nd@byđongevialle@t@1.đor@teroids [12].@More@recently, @his@oncept Chas@een@ipplied@o positively-charged $\$ 13] @$ nd@egatively-charged $\$ 14, @ 5]$ even-electron molecular systems and in particular to peptide dissociations [15]. Formation of ion-neutral as intermediates has been shown to imply a chargepromoted cleavage process that can be accompanied by a proton transfer on both partners of the complex, 
according to gas-phase chemical considerations (i.e., basicity/acidity).

Microcins form a peculiar class of gene-encoded low-molecular-weight antibacterial peptides secreted by Enterobacteria [16]. Microcin C7-C51 (MccC7-C51) is the smallest microcin isolated to date (Scheme 1a). It is a ribosomally-synthesized $\mathrm{N}$-formylated heptapeptide including a C-terminal aspartic acid, which is covalently linked to a phosphoramidate group, itself substituted with both an adenosine moiety and a propylamine chain [17]. MccC7-C51 activity involves an original mechanism of "Trojan horse" type [18, 19], where the microcin is allowed to enter, freely target bacteria, and is transformed when inside into a toxic entity. Indeed, a specific cleavage occurs inside the target bacteria at the microcin Ala6-Asp7 peptide bond that yields a modified aspartyl-adenylate named MccC7-C51* (Scheme 1b). This entity, which is the actual intracellularly active form of the microcin, is an inhibitor of translation [18]. It can be generated in vitro by specific enzymatic cleavage [18]. MccC7-C51, which is composed of two distinct parts, a peptidic moiety (the heptapeptide that we term PepC7-C51) (Scheme 1c) and a modified nucleotide moiety connected through a phosphoramidate bond, thus offering a unique opportunity to study the fragmentation of nucleotide peptides. Indeed, the peptide and nucleotide parts can be analyzed either independently, using the heptapeptide PepC7-C51 and the modified nucleotide MccC7-C51*, or associated in the native MccC7-C51.

Here, we report the characterization of the nucleotide peptide MccC7-C51, of the corresponding unmodified heptapeptide PepC7-C51, and of the derived translation inhibitor MccC7-C51* by ESI-MS, to afford keys to nucleotide peptide structural elucidation. Fragmentation patterns were analyzed in both the positive- and negative-ion modes. To demonstrate the fragmentation mechanisms proposed, experiments were performed using the recently-introduced high-resolution LTQ Orbitrap instrument, which consists of a hybrid linear quadrupole ion trap (LTQ) coupled to the novel Fouriertransform (FT) analyzer Orbitrap [20-24]. Finally, different mechanistic aspects that drive the fragmentations are proposed through the formation of ion-dipole complexes. In particular, the occurrence of zwitterionic-like species, which strongly influence the orientation of the fragmentations promoted by the charge, is discussed [25].

\section{Experimental}

\section{Materials}

The formylated peptide f-MRTGNAD-NH ${ }_{2}$ (PepC7C51) was obtained from Genepep (Montpellier, France) purity $>95 \%$ checked by high-performance liquid chromatography (HPLC) and mass spectrometry.

\section{Production and Purification of MccC7-C51 and MccC7-C51*}

The E. coli strain TG1 harboring the MccC7-C51 plasmid pBM43 was grown for $18 \mathrm{~h}$ at $37^{\circ} \mathrm{C}$ in M63 minimum medium. The cells were removed by centrifugation $(20$ min at 10,000 g) and the supernatant was loaded onto a C18 solid-phase extraction cartridge (SepPak; Waters Corp., Saint Quentin en Yvelines, France), conditioned with $\mathrm{MeOH}$ and equilibrated with $0.1 \%$ aqueous trifluoroacetic acid (TFA). The cartridge was washed with $0.1 \%$ aqueous TFA and the elution was performed stepwise with $5 \%, 10 \%, 15 \%$, and $20 \% \mathrm{MeOH}$ in $0.1 \%$ aqueous TFA. The $15 \% \mathrm{MeOH}$ fraction was dried under vacuum, reconstituted in water, and subjected to reversed-phase highperformance liquid chromatography (RP-HPLC) on a C18 column (Capcell $5 \mu \mathrm{m}, 4.6 \times 250 \mathrm{~mm}$; Interchim, Montluçon, France) using a $0 \%$ to $15 \%$ linear gradient of acetonitrile in $0.1 \%$ TFA at a flow rate of $1 \mathrm{~mL} / \mathrm{min}$. Absorbance was monitored at a $\lambda$ of $226 \mathrm{~nm}$ and the microcin fraction was collected manually.

To obtain MccC7-C51*, MccC7-C51 was incubated for $2 \mathrm{~h}$ in $10 \mathrm{mM}$ ammonium acetate buffer, $\mathrm{pH}$ 6.5, in (a)

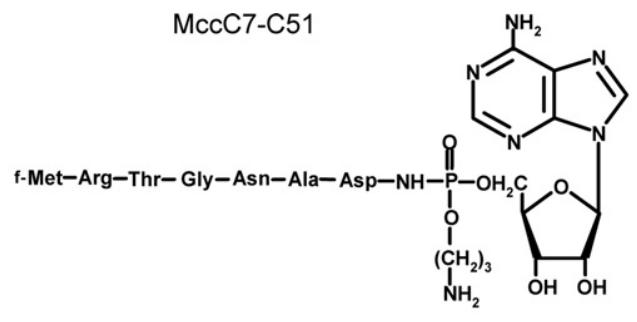

PepC7-C51

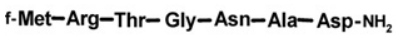

(b) (c)

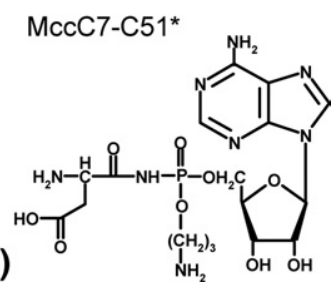


the presence of endoproteinase Asp-N at an enzyme/ substrate ratio of $1 / 200(w t / w t)$. The reaction mixture was subjected to RP-HPLC on a C18 column (Capcell 5 $\mu \mathrm{m}, 4.6 \times 250 \mathrm{~mm}$; Interchim) using a $0 \%$ to $25 \%$ linear gradient of acetonitrile in $0.1 \%$ TFA at a flow rate of 1 $\mathrm{mL} / \mathrm{min}$. Absorbance was monitored at a $\lambda$ of $226 \mathrm{~nm}$ and the MccC7-C51* fraction was collected manually.

\section{Mass Spectrometry}

MccC7-C51, MccC7-C51* and PepC7-C51 samples were analyzed at concentrations of 10 or $100 \mathrm{pmol} / \mu \mathrm{L}$ in 10 $\mathrm{mM}$ ammonium acetate buffer $\mathrm{pH}$ 6.5. The ESI-MS analyses were carried out on a Qq-TOF/MS instrument (Q-Star Pulsar; Applied Biosystems, Courtaboeuf, France) and a LTQ Orbitrap instrument [19-23] (Thermo Electron, les Ulis, France) operated in positive- and negative-ion modes. The Qq-TOF instrument was equipped with a nanospray source and operated with capillary voltage values between 800 and $1100 \mathrm{~V}$. When appropriate, the declustering potential was optimized to favor the formation of $\mathrm{m} / \mathrm{z} 445$ and 630 product ions by "in source CID processes" from the nanoESI experiments. For CID experiments of selected ions in the Qq-TOF analyzer, the collision energy varied between 5 and 50 $\mathrm{V}$. Accurate mass measurements were performed on the LTQ Orbitrap instrument. MccC7-C51 or PepC7-C51 solutions were introduced into the ESI source at a flow rate of $5 \mu \mathrm{L} / \mathrm{min}$ and the instrument was operated in positive- and negative-ion modes with a spray voltage of $3 \mathrm{kV}$. When necessary, the tube lens voltage was optimized to favor in source-fragmentations resulting in the $m / z 445$ and 630 product ions. The $m / z 212$ and 214 ions were used as internal lock mass calibrants in negative- and positive-ion modes, respectively. For CID experiments in the LTQ cell, the standard technique for ion fragmentation by resonant excitation was used. The amplitude voltage of the axial excitation was standardized by using normalized collision energy (NCE) increasing from $15 \%$ to $60 \%$ [22]. A mass accuracy of 2 ppm and $\sim 10$ ppm was observed on the LTQ Orbitrap and on the Qq-TOF/MS instruments, respectively.

\section{Results and Discussion}

Positive Ions Generated from MccC7-C51, MccC7C51*, and PepC7-C51 in the ESI Source with Low Collision Energy

Positive ions generated under ESI conditions. A comparative analysis of the ESI spectra of MccC7-C51, MccC7C51*, and PepC7-C51 was performed on the ESI-Qq-TOF. The detected ions and their corresponding relative abundances are summarized in Table 1. Under the ESI conditions used, the positive-ion mode ESI mass spectrum of MccC7-C51 displayed $[\mathrm{Mc}+2 \mathrm{H}]^{2+}$ as base peak, together with the corresponding cationized $[(\mathrm{Mc}+\mathrm{H})+\mathrm{Na}]^{2+}$ and the minor triply protonated $[\mathrm{Mc}+3 \mathrm{H}]^{3+}$ species. Furthermore, a product ion assigned to the protonated peptide
Table 1. Main ions displayed on the ESI mass spectra of MccC7-C51, PepC7-C51, MccC7-C51* in positive (a) and negative (b) ion modes

Compounds $\quad \mathrm{m} / \mathrm{z}$ and relative intensities (\% of base peak)

(a)

MccC7-C51

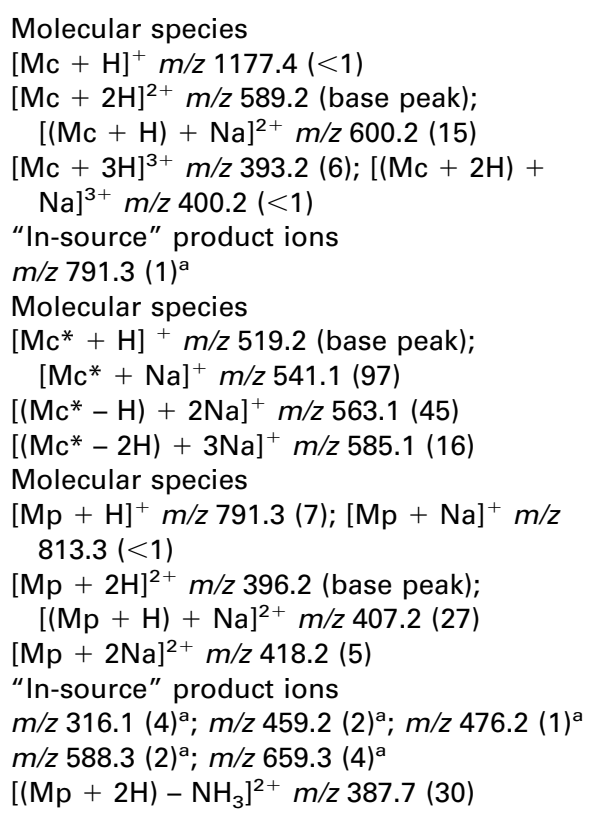

(b)

MccC7-C51

Molecular species

$[\mathrm{Mc}-\mathrm{H}]^{-} \mathrm{m} / \mathrm{z} 1175.5(<1)$

$[\mathrm{Mc}-2 \mathrm{H}]^{2-} \mathrm{m} / \mathrm{z} 587.2$ (base peak);

$[(\mathrm{Mc}-3 \mathrm{H})+\mathrm{Na}]^{2-} \mathrm{m} / \mathrm{z} 598.2(10)$

"In-source" product ions

$m / z 789.3(<1)^{a}$

MccC7-C51* Molecular species

$\left[\mathrm{Mc}^{*}-\mathrm{H}\right]^{-} \mathrm{m} / \mathrm{z} 517.2$ (base peak);

$\left[\left(\mathrm{Mc}^{*}-2 \mathrm{H}\right)+\mathrm{Na}\right]^{-} \mathrm{m} / \mathrm{z} 539.2(27)$

"In-source" product ions

$\mathrm{m} / \mathrm{z} 402.2(10)^{\mathrm{a}}$

PepC7-C51 Molecular species

$[\mathrm{Mp}-\mathrm{H}]^{-} \mathrm{m} / \mathrm{z} 789.3$ (27)

$[\mathrm{Mp}-2 \mathrm{H}]^{2-} \mathrm{m} / \mathrm{z} 394.1(63)$

"In-source" product ions

$\mathrm{m} / \mathrm{z} 363.1(1)^{\mathrm{a}} ; \mathrm{m} / \mathrm{z} 445.2(2)^{\mathrm{a}}$

$[(\mathrm{Mp}-2 \mathrm{H})-44]^{2-} \mathrm{m} / \mathrm{z} 372.1$ (base peak)

a Singly-charged product ions.

$(m / z$ 791), resulting from the "in-source" release of the modified nucleotide moiety, was also observed in low abundance (Table 1a). By contrast, the ESI mass spectrum of MccC7-C51* only displayed the monoprotonated $\left[\mathrm{Mc}^{*}+\mathrm{H}\right]^{+}$as base peak, accompanied by several cationized species, $\left[\mathrm{Mc}^{*}+\mathrm{Na}\right]^{+},\left[\left(\mathrm{Mc}^{*}-\mathrm{H}\right)+2 \mathrm{Na}\right]^{+}$and $\left[\left(\mathrm{Mc}^{*}\right.\right.$ $-2 \mathrm{H})+3 \mathrm{Na}]^{+}$. "In-source" product ions were not detected: this may be due to the absence of the doubly charged $\left[\mathrm{Mc}^{*}+2 \mathrm{H}\right]^{2+}$ species, which is less stable than the singly charged one. The ESI-mass spectrum of PepC7C51 displayed a similar trend to that of MccC7-C51, with the doubly protonated $[\mathrm{Mp}+2 \mathrm{H}]^{2+}$ as base peak, as well as the corresponding cationized $[(\mathrm{Mp}+\mathrm{H})+\mathrm{Na}]^{2+}$ species. The monoprotonated $[\mathrm{Mp}+\mathrm{H}]^{+}$and the cationized $[\mathrm{Mp}+\mathrm{Na}]^{+}$and $[\mathrm{Mp}+2 \mathrm{Na}]^{2+}$ species were also 


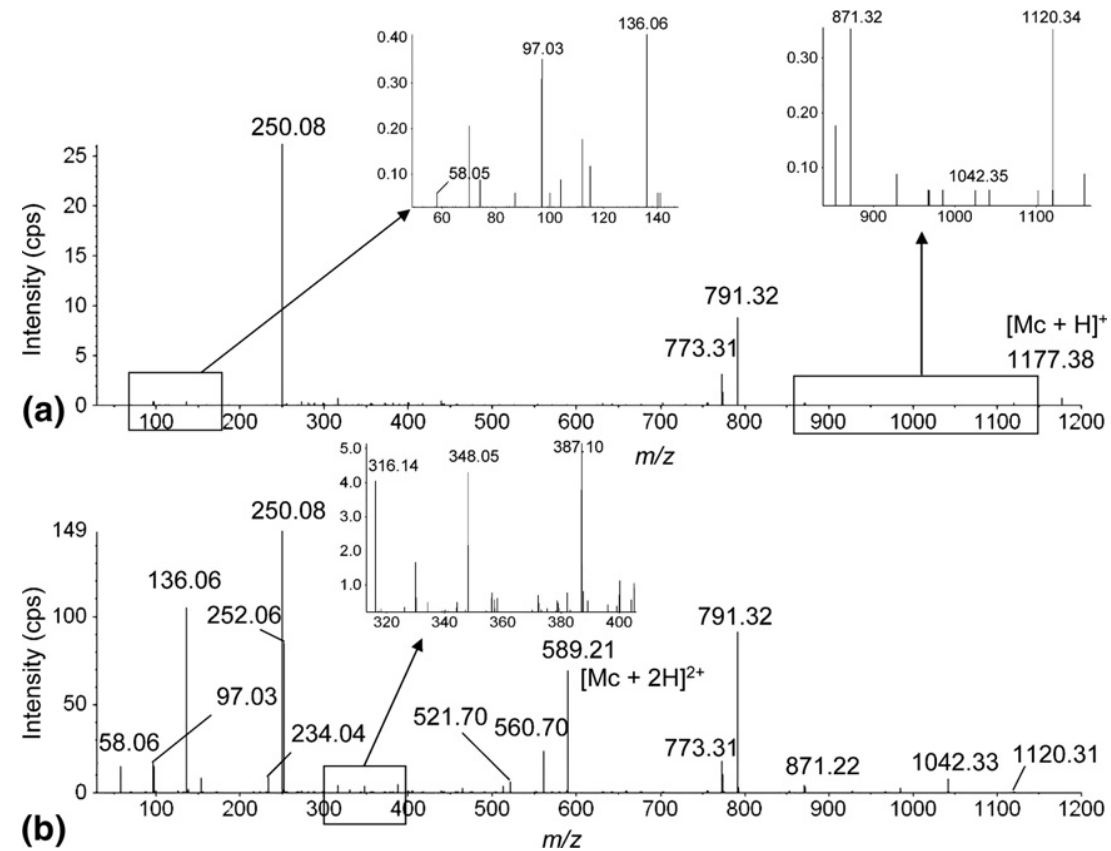

Figure 1. Positive-ion mode CID spectra of MccC7-C51 obtained from $100 \mathrm{pmol} / \mu \mathrm{L}$ solution in 10 $\mathrm{mM}$ ammonium acetate buffer $\mathrm{pH} 6.5$ recorded on the ESI-Qq-TOF instrument. (a) Selection of [Mc + $\mathrm{H}]^{+}$at $m / z 1177, \mathrm{Ec}=50 \mathrm{eV}$. (b) Selection of $[\mathrm{Mc}+2 \mathrm{H}]^{2+}$ at $m / z 589, \mathrm{Ec}=80 \mathrm{eV}$.

detected in low abundance. In addition, the doubly charged $\left[(\mathrm{Mp}+2 \mathrm{H})-\mathrm{NH}_{3}\right]^{2+}$ product ion, which results from a prompt "in-source" $\mathrm{NH}_{3}$ loss, was observed. The occurrence of such an unusual $\mathrm{NH}_{3}$ loss suggests that the positive charge was located at the C-terminal side of the peptide, given that the N-terminus is formylated. Several low-abundance diagnostic ions were also detected at $\mathrm{m} / \mathrm{z}$ 316, 459, 476, 588, and 659 (Table 1a), which also resulted from "in-source" peptide fragmentation.

To get a comprehensive view of the gas-phase fragmentations of nucleotide peptides and nucleotide moieties compared with those of the corresponding unmodified peptides, low-energy CID processes were conducted on the molecular species arising from MccC7-C51, MccC7-C51*, and PepC7-C51 (Figure 1, Figure 2, and Figure 3).

Product Ions Generated Under Low Collision Energy from Protonated Species. CID experiments were carried out on the three MccC7-C51 molecular species, $[\mathrm{Mc}+\mathrm{H}]^{+}$ $\left(m / z\right.$ 1177), $[\mathrm{Mc}+2 \mathrm{H}]^{2+}(m / z 589)$ (Figure 1) and $[\mathrm{Mc}+$ $3 \mathrm{H}]^{3+}(\mathrm{m} / \mathrm{z} 393)$ (data not shown). The major product ions $(\mathrm{m} / \mathrm{z} 791,773$, and 250$)$ of the CID spectra were formed from the two precursor ions $[\mathrm{Mc}+\mathrm{H}]^{+}$and $[\mathrm{Mc}$ $+2 \mathrm{H}]^{2+}$, together with other weaker product ions at $m / z$ 1120, 1042 and 871. The $m / z 560$ and 521 product ions displayed in the CID spectrum of $[\mathrm{Mc}+2 \mathrm{H}]^{2+}$, were assigned to the doubly charged species corresponding to the singly charged species at $m / z 1120$ and 1042, respectively. Finally, the product ion at $m / z 136$ was observed with a high abundance from the [Mc + $2 \mathrm{H}]^{2+}$ precursor ion, and with a weaker abundance from the $[\mathrm{Mc}+\mathrm{H}]^{+}$precursor ion. Indeed, the essential difference between the product ion spectra of the singly- and doubly charged MccC7-C51 species was the presence of the $m / z 252$ ion, arising from dissociation of $[\mathrm{Mc}+2 \mathrm{H}]^{2+}$ and not from $[\mathrm{Mc}+\mathrm{H}]^{+}$. In addition, the singly charged $\mathrm{m} / \mathrm{z} 97$ and $\mathrm{m} / \mathrm{z} 58$ product ions displayed in the CID spectrum of $[\mathrm{Mc}+2 \mathrm{H}]^{2+}$ were detected with a weak abundance from the $[\mathrm{Mc}+\mathrm{H}]^{+}$ precursor ion, while the $m / z 234$ product ion was only observed in the CID spectrum of $[\mathrm{Mc}+2 \mathrm{H}]^{2+}$. Taking into account these whole results, we propose a series of decomposition pathways of MccC7-C51, considering that several peaks can be associated (1) by pairs of product ions (noted $\mid m / z \times x x / / m / z$ yyy $\mid$ ), that are

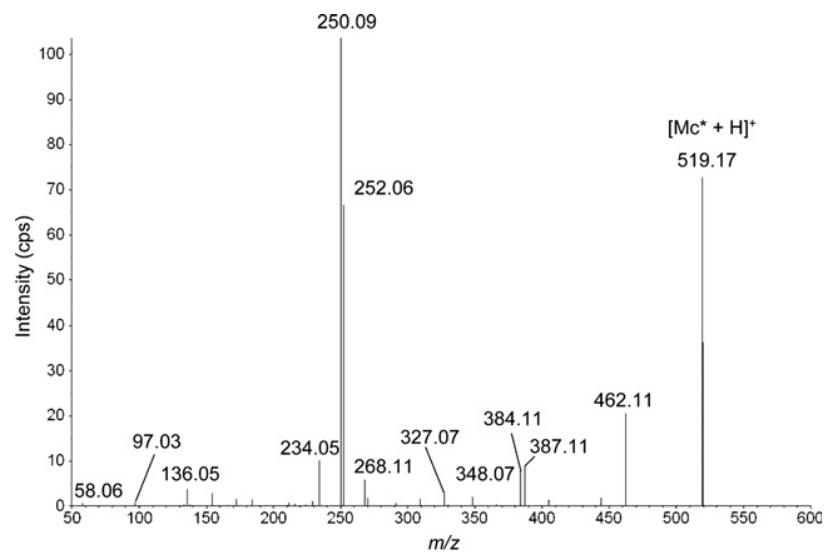

Figure 2. Positive-ion mode CID spectrum of MccC7-C51* ([Mc* $+\mathrm{H}]^{+}$at $m / z 519$ ) obtained from $100 \mathrm{pmol} / \mu \mathrm{L}$ solution in $10 \mathrm{mM}$ ammonium acetate buffer $\mathrm{pH} 6.5$ recorded on the ESI-Qq-TOF instrument $(\mathrm{Ec}=30 \mathrm{eV})$. 


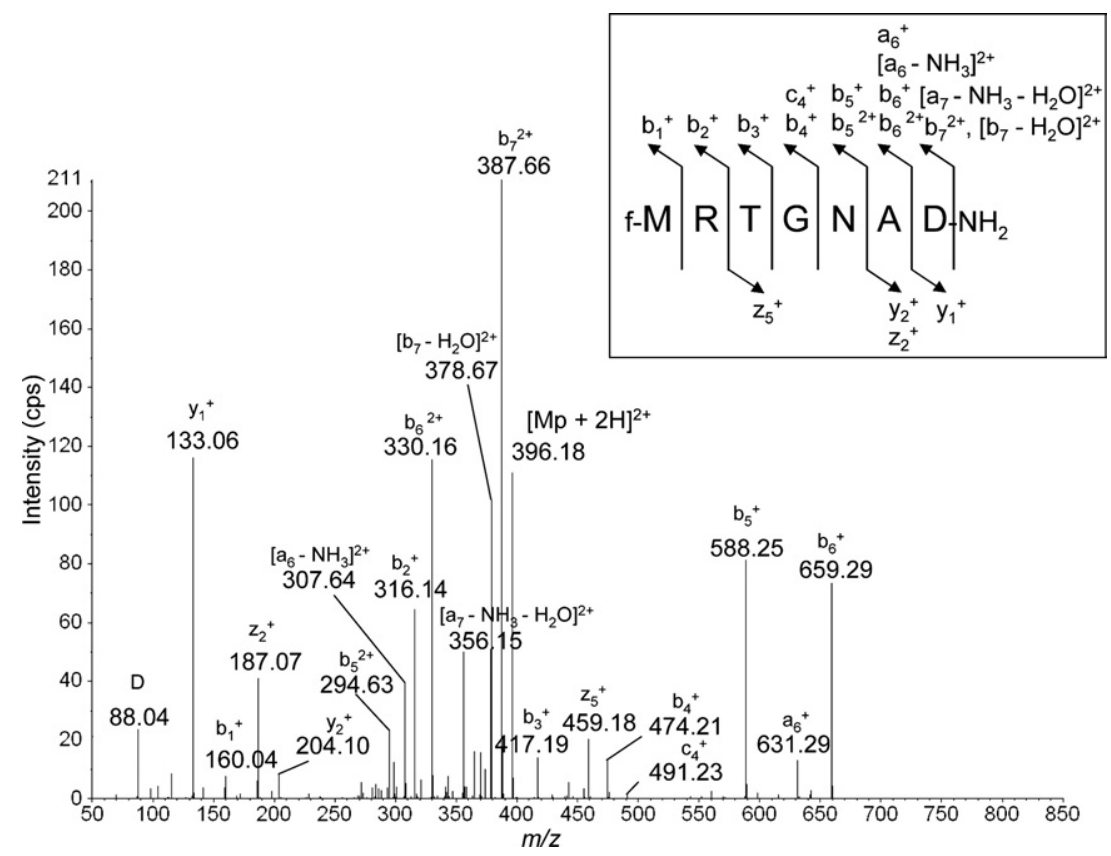

Figure 3. Positive-ion mode CID spectrum of PepC7-C51 $\left([\mathrm{Mp}+2 \mathrm{H}]^{2+}\right.$ at $\mathrm{m} / z$ 396) obtained from 100 $\mathrm{pmol} / \mu \mathrm{L}$ solution in $10 \mathrm{mM}$ ammonium acetate buffer $\mathrm{pH} 6.5$ recorded on the ESI-Qq-TOF instrument $(\mathrm{Ec}=40 \mathrm{eV})$.

related to direct cleavages of the selected precursor ion (e.g., $\left.[\mathrm{Mc}+2 \mathrm{H}]^{2+}\right)$, or (2) by ion-dipole complexes (noted $\{m / z$ xxx/yyy $\mathbf{u}\}$ ) that result from isomerization of the singly charged ion before consecutive dissociations. These non covalent species can either directly dissociate or yield complementary ions via internal proton transfer. Thus, three pairs of complementary product ions due to charge separation processes can be formed from the $[\mathrm{Mc}+2 \mathrm{H}]^{2+}$ precursor ion $(m / z 589)$ : $|\mathrm{m} / \mathrm{z} 1042 / / \mathrm{m} / \mathrm{z} 136|,|\mathrm{m} / \mathrm{z} 791 / / \mathrm{m} / \mathrm{z} 387|$ and $\mid \mathrm{m} / \mathrm{z}$ $1120 / / m / z 58 \mid$ ), which define three stepwise dissociation pathways noted $\boldsymbol{a}, \boldsymbol{b}$, and $\boldsymbol{c}$ (Scheme 2):

1. In the $\boldsymbol{a}$ pathway, the $\mathrm{m} / \mathrm{z} 1042$ product ion may isomerize via the $\boldsymbol{a}_{2}$ process into the $\underline{\mathbf{A}}_{2}$ ion-dipole before dissociation (vide infra). This occurs from phosphate cleavage assisted by a nucleophilic attack of the propylamine side chain $\mathrm{NH}_{2}$ group followed by proton transfer to the peptide to give rise to the formation of the $\mathrm{m} / \mathrm{z} 791$ ion, corresponding to the protonated heptapeptide. From the $\underline{\mathbf{A}}_{2}$ ion-dipole, internal proton transfer from the peptide to the modified phosphate group yields the $\mathrm{m} / \mathrm{z} 252$ product ion of second generation. After $\underline{\mathbf{A}}_{2}{ }^{\prime}$ ion-dipole dissociation, the $\mathrm{m} / \mathrm{z} 252$ product ion is able to undergo the consecutive release of (1) a water molecule $\left(\mathbf{a}_{3}\right.$ step) and (2) the $\mathrm{O}=\mathrm{P}\left[\mathrm{O}\left(\mathrm{CH}_{2}\right)_{3} \mathrm{~N}\right]$ modified phosphate group ( $\mathbf{a}_{4}$ step), to yield the $\mathrm{m} / \mathrm{z}$ 234 and 97 (a protonated furane-2-aldehyde) ions. These consecutive dissociations of $\mathrm{m} / \mathrm{z} 1042$ explain the low abundance of this ion compared with its complementary product ion at $\mathrm{m} / \mathrm{z} 136$.
2. In the $\boldsymbol{b}$ pathway, the first step $\boldsymbol{b}_{\mathbf{1}}$ consists of charge parting yielding the $\mathrm{m} / \mathrm{z} 387$ and the complementary $\mathrm{m} / \mathrm{z} 791$ product ions. The former can consecutively isomerize through a proton transfer to the adenosine moiety into the $\underline{B}_{2}$ ion-dipole via the $\boldsymbol{b}_{2}$ process, before dissociating and either directly yield the $\mathrm{m} / \mathrm{z} 252$ ion, or lead to protonated adenosine $(\mathrm{m} / \mathrm{z}$ 136), after reversible internal proton transfer ( $\underline{\mathbf{B}}_{2} \rightleftarrows \underline{\mathbf{B}}_{2}^{\prime}$, isomerization).

3. A similar stepwise process describes the $\mathbf{c}$ pathway, for which the first cleavage step $c_{1}$ occurs by charge repulsion to yield the complementary $\mathrm{m} / \mathrm{z} 58$ and 1120 product ions. The latter is observed with a very weak abundance, which is explained by considering its possible isomerization ( $c_{2}$ step) into the $\boldsymbol{C}_{2}$ iondipole, yielding either directly the $\mathrm{m} / \mathrm{z} 250$ product ion (protonated dehydrated adenosine) or after internal proton transfer, the $\mathrm{m} / \mathrm{z} 871$ product ion $\left(\underline{\mathbf{C}}_{2}{ }^{\prime}\right.$ ion-dipole). Dephosphorylation of the $m / z 871$ species from the $\mathbf{C}_{2}{ }^{\prime}$ ion-neutral complex generates the protonated heptapeptide $(\mathrm{m} / \mathrm{z} 791)$ via the $c_{3}$ process. The latter, independently of its origin (i.e., $a_{2}$, $b_{1}, c_{3}$ processes) can lose a water molecule to yield the $\mathrm{m} / \mathrm{z} 773$ product ion. Note that it cannot be ruled out that the $\mathrm{m} / \mathrm{z} 250$ product ion may also arise from the $m / z 387$ ion $\left(\boldsymbol{b}_{\mathbf{2}^{\prime \prime}}\right.$ step). The former can yield directly the $m / z 136$ product ion ( $\boldsymbol{c}_{2}{ }^{\prime \prime}$ step).

The dissociation pathways of the singly charged [Mc + $\mathrm{H}^{+}$species $(m / z$ 1177) occur via similar stepwise processes (noted $\boldsymbol{a}, \boldsymbol{b}$, and $\boldsymbol{c}$ ) to those of the doubly charged $[\mathrm{Mc}+2 \mathrm{H}]^{2+}$ ion, the main difference being due to the 


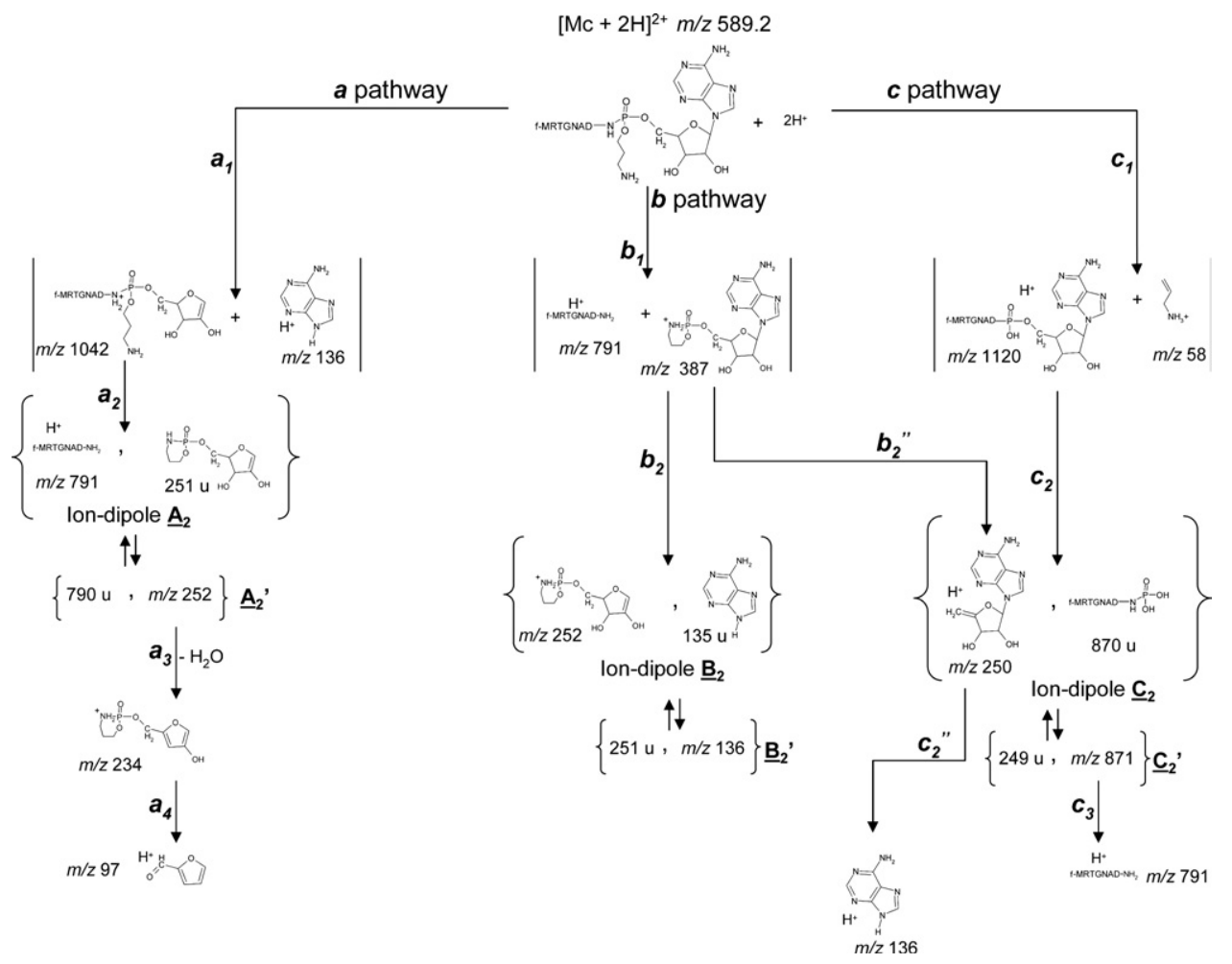

Scheme 2

single charge of the precursor ion. The first step yields directly the isomerized $\underline{\mathbf{A}}_{1}, \underline{\mathbf{B}}_{1}$, and $\underline{\mathbf{C}}_{1}$ ion-dipole complexes (Scheme 3). The CID spectrum of $[\mathrm{Mc}+\mathrm{H}]^{+}$ appears less complex than that of $[\mathrm{Mc}+2 \mathrm{H}]^{2+}$, due to the decreased number of consecutive dissociation processes. The main species detected are the $m / z 791$ and 250 (base peak) product ions (Figure 1a). The former dissociates into $\mathrm{m} / \mathrm{z} 773$ by water release. The CID

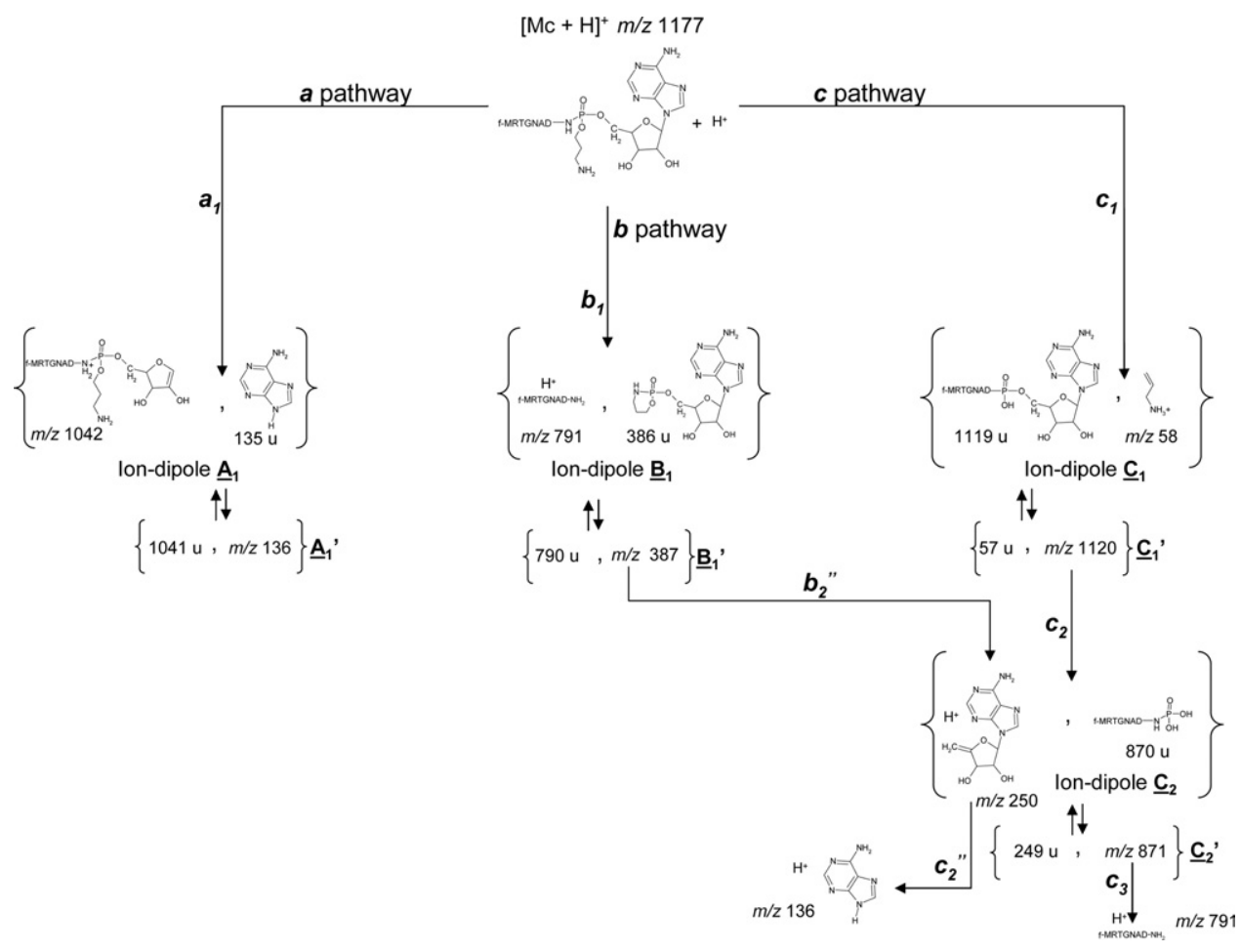

Scheme 3 
spectrum of the triply-charged $[\mathrm{Mc}+3 \mathrm{H}]^{3+}$ species can be rationalized similarly, by considering the formation of pairs of product ions and isomerizations into iondipole complexes (data not shown). Interestingly, the $\mathrm{m} / \mathrm{z} 250$ and 252 product ions are observed in competition on the CID spectra of MccC7-C51, depending on the charge carried by the precursor ions. The product ion at $m / z 250$ is observed in the CID spectrum of [Mc + $2 \mathrm{H}]^{2+}$ (Figure 1b), together with the competing product ion at $m / z 252$. However, of these two ions, only $m / z 252$ is detected on the CID spectrum of $[\mathrm{Mc}+3 \mathrm{H}]^{3+}$, while only $\mathrm{m} / \mathrm{z} 250$ is detected in the CID spectrum of [Mc + $\mathrm{H}]^{+}$. Thus, the $m / z 252$ ion appears to be favored when the charge state of the precursor ion increases, which reflects the role of the charge on dissociation processes involving charge repulsion. Thus, both the charge location (either at the peptide C-terminus, or next to the phosphate group, or at the nucleoside group) and distribution govern the orientation of product ion pair formation through proton migration processes.

Similarly, the fragmentation pattern of the modified aspartyl-adenylate MccC7-C51* strongly relies on the location of the positive charge (Figure 2). The charge appears to be located either at the amino group of the aspartic acid residue, or of the propylamine chain, or at the nucleotide moiety. As for MccC7-C51, several product ions can be produced from the singly charged [ $\mathrm{Mc}^{*}$ $+\mathrm{H}]^{+}$precursor ion via stepwise processes through isomerization into ion-dipole complexes: $(\{\mathrm{m} / \mathrm{z} 136 / 383$ $\mathrm{u}\},\{m / z 58 / 461 \mathrm{u}\}$ ) (Scheme 4). Three competing fragmentation pathways are thus proposed for MccC7C51*:
1. The $\boldsymbol{a}_{\mathbf{1}}$ step yields the $\{m / z 136 / 383 \mathrm{u}\} \underline{\mathbf{A}}_{1}$ iondipole. The aspartic acid release from the $\mathrm{m} / \mathrm{z} 384$ product ion leads consecutively to the $\mathrm{m} / \mathrm{z} 252$ product ion ( $a_{2}$ step). As for the microcin, the latter generates the $m / z 234$ ( $\boldsymbol{a}_{3}$ step) and consecutively the $m / z 97\left(a_{4}\right.$ step) product ions. The $m / z 384$ product ion is able to undergo dissociation, yielding the $\underline{\mathbf{A}}_{5}$ ion-dipole (i.e., $\{m / z 58 / 326 u\}$ ) via the $\boldsymbol{a}_{5}$ process.

2. In the $\boldsymbol{b}$ pathway, the $m / z 387$ product ion can isomerize into the $\underline{\mathbf{B}}_{2}$ ion-dipole complex through the nucleobase release to yield the $m / z 252$ species ( $\boldsymbol{b}_{\mathbf{2}}$ step).

3. In the $c$ pathway, a similar isomerization generates the $\mathbf{C}_{1}$ ion-dipole complex constituted by the protonated propenylamine and aspartic-AMP neutral $\left(c_{1}\right.$ step), and subsequent isomerization by internal proton transfer yields the $\mathrm{m} / \mathrm{z} 462$ ion. The latter yields the protonated adenosine monophosphate at $\mathrm{m} / \mathrm{z} 348\left(\boldsymbol{c}_{\mathbf{4}}\right.$ step) through aspartic acid cyclization and release. The $m / z 348$ ion can consecutively lose the phosphate group $\left(c_{6}\right.$ step) to yield the $m / z 268$ ion as protonated adenosine. The latter can consecutively lose a water molecule and the ribose group, to yield $m / z 250$ (protonated dehydrated adenosine) as base peak ( $\boldsymbol{c}_{\mathbf{7}}$ step) and $m / z 136\left(\boldsymbol{c}_{\mathbf{2}}{ }^{\prime \prime}\right.$ step), respectively. The $m / z 462$ ion can also generate the $\underline{\mathbf{C}}_{5}$ ion-dipole ( $\{m / z$ 136/326 u $\})$ and after proton transfer, the $\underline{C}_{5}{ }^{\prime}$ ion-dipole. As previously noticed for MccC7-C51, the $m / z 250$ and 252 product ions are formed in competition, depending upon the charge state of the selected precursor ions (data not shown). The results obtained with protonated

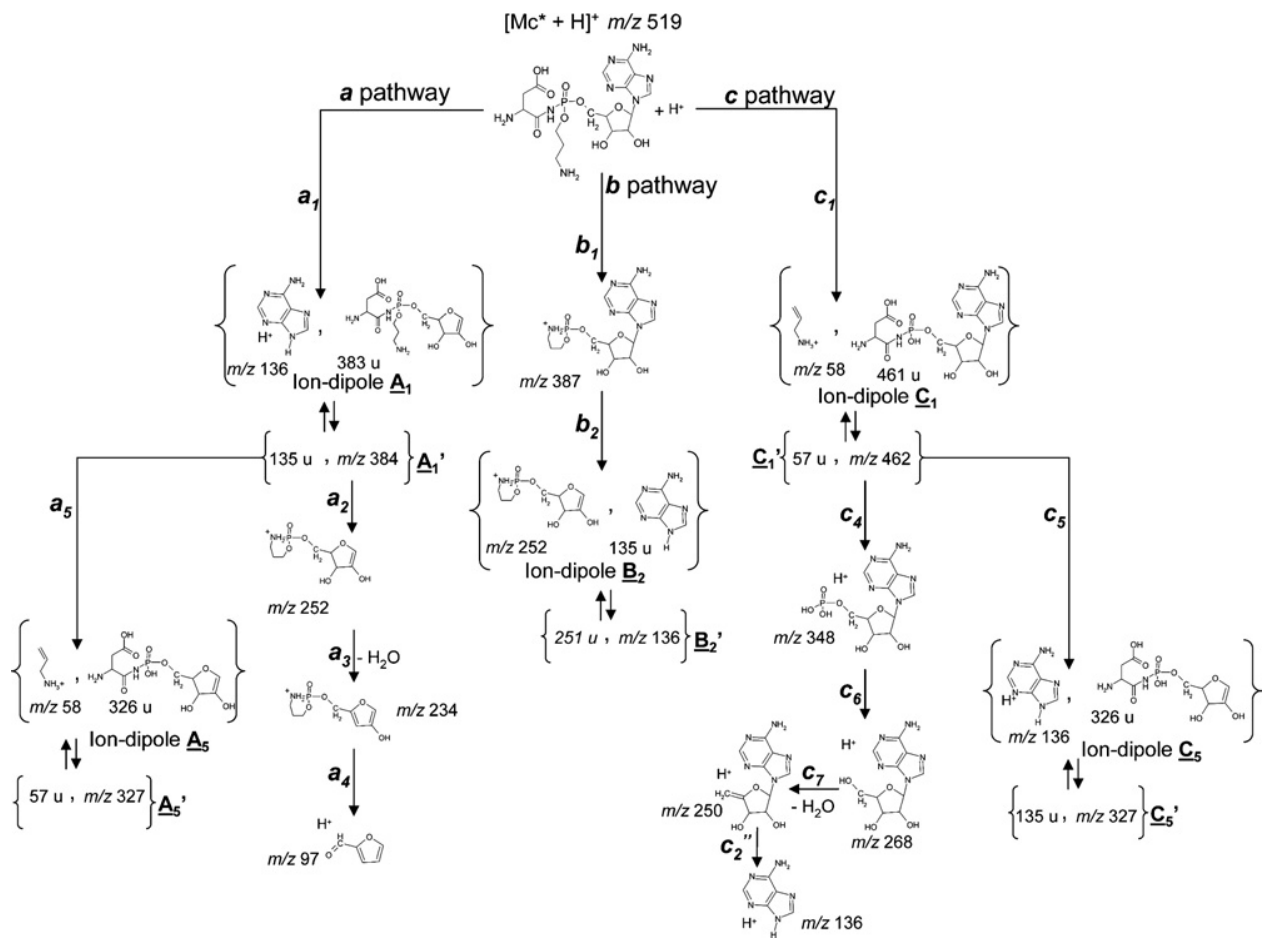

Scheme 4 
MccC7-C51 and MccC7-C51* show that, for such even-electron complex systems, the isomerization into ion-dipole complexes takes place before dissociation. This behavior is well known for a large class of chemical compounds including organic and biological molecules, such as certain amino steroids [12], glycoconjugates [14], steroid fatty acids [26], DNA adduct steroids [13], lipopolysaccharides [27], and peptides [28]. If the complex life time is sufficiently large, due to the relative low internal energy compared to the dissociation energy threshold, internal proton transfer can occur, resulting from the formation of complementary ion pairs. Note that such isomerizations at the first step of the fragmentation pathways, yielding ionneutral complexes, can be generalized to rationalize the fragmentation patterns of certain proteinRNA cross-links analyzed by post-source decay (PSD) experiments [3, 4].

The fragmentation pattern of PepC7-C51 was investigated to interpret certain fragmentation mechanisms observed for protonated MccC7-C51. The CID spectrum of the doubly protonated PepC7-C51 $\left([\mathrm{Mp}+2 \mathrm{H}]^{2+}, \mathrm{m} / z\right.$ 396) (Figure 3) resulted in a b-type ion series $(\mathrm{m} / \mathrm{z} 160$, 294, 316, 330, 378, 387, 417, 474, 588, and 659), a-type ions at $m / z 307,356$, and 631, and a weak c-type ion at $\mathrm{m} / \mathrm{z}$ 491. Furthermore, y-type ions at $\mathrm{m} / \mathrm{z} 133$ and 204 and two unexpected z-type ion at $m / z 187$ and 459 were observed $[29,30]$. Note that when the skimmer potential was increased, the $\boldsymbol{b}_{2}^{+}$ion at $m / z 316$ became the dominant product ion (data not shown). The unmodified peptide PepC7-C51 contains a basic residue at the N-terminal side (Arg), which is susceptible to retain the charge in this region, thus favoring $a$ and $b$ product ions [31]. This is consistent with the fragmentation pattern observed, with a majority of b-type ions. However, once the protonated peptide has been desorbed into the gas phase, proton transfer to the carbonyl oxygen, the backbone amide nitrogen atoms, or to certain side-chain functional groups becomes possible, particularly upon collisional activation [32]. The presence of the complementary $\mathrm{z}$ and $\mathrm{c}$ product ions, which are normally observed at high collision energy, show that PepC7-C51 is prone to undergo fragmentation, as illustrated by its tendency to produce diagnostic ions "in source".

From the whole data provided by the CID spectra, the fragmentation of MccC7-C51 in positive ion mode seems to result in two different sorts of product ions: a class containing the peptide moiety and another one consisting of nucleotide derivatives. Few peptide diagnostic ions are observed, while a loss of PepC7-C51, adenine, and/or the propylamine chain are favored. Therefore, the study of MccC7-C51 in positive-ion mode provides mostly information on the nucleotide part of the molecule.
Negative Ions Generated in the ESI Source and Under Low Collision Energy for MccC7-C51, MccC7-C51*, and PepC7-C51

Negative ions generated under ESI conditions. The mass spectrum of MccC7-C51 in negative-ion mode displayed a trend similar to that observed in positive-ion mode. The doubly charged $[\mathrm{Mc}-2 \mathrm{H}]^{2-}$ and the $[(\mathrm{Mc}-$ $3 \mathrm{H})+\mathrm{Na}]^{2-}$ molecular species were the major ions detected (Table 1b). The negative-ion ESI-mass spectrum of MccC7-C51* displayed both the $\left[\mathrm{Mc}^{*}-\mathrm{H}\right]^{-}$ (base peak) and $\left[\left(\mathrm{Mc}^{*}-2 \mathrm{H}\right)+\mathrm{Na}\right]^{-}$species. Note that a product ion at $m / z 402$ was observed, which corresponded to a loss of aspartic acid from MccC7-C51* (Table 1b).

The ESI-mass spectrum of PepC7-C51 showed mainly the doubly deprotonated $[\mathrm{Mp}-2 \mathrm{H}]^{2-}$ and $[\mathrm{Mp}$ $-\mathrm{H}]^{-}$species, together with minor product ions at $\mathrm{m} / \mathrm{z}$ 363 and 445 . Interestingly, an unexpected base peak was detected at $m / z 372$, which corresponded to a loss of $44 \mathrm{u}$ from the $[\mathrm{Mp}-2 \mathrm{H}]^{2-}$ species. Such a $44-\mathrm{u}$ neutral loss is generally attributed to a $\mathrm{CO}_{2}$ release [33]. However, high resolution analysis of the $m / z 372$ ion, using the LTQ Orbitrap instrument, permitted to assign unambiguously this neutral loss to an elemental composition of $\mathrm{C}_{2} \mathrm{H}_{4} \mathrm{O}$, corresponding to the release of $\mathrm{CH}_{3} \mathrm{CHO}$ from the threonine side chain. Such a result, discussed below in the CID data section, was previously reported by Steinborner and Bowie. [33]. Note that this neutral loss takes place exclusively from the doubly deprotonated peptide and not from the deprotonated [Mp $\mathrm{H}]^{-}$species. To explain this difference in behavior, two possible situations can be considered during the desolvation of charged aggregates at the skimmer. The first way assumes that the $\mathrm{C}_{2} \mathrm{H}_{4} \mathrm{O}$ release takes place "in source" before the aggregate ion desolvation, to yield the solvated $[(\mathrm{Mp}+\mathrm{xs}-2 \mathrm{H})-44]^{2-}$ product ion (xs corresponds to $x$ molecules of solvent). If this way would operate, observation of both the $[(\mathrm{Mp}-2 \mathrm{H})-$ $44]^{2-}$ and $[(\mathrm{Mp}-\mathrm{H})-44]^{-}$product ions should be possible after solvent release as $\mathrm{xs}$ and $[\mathrm{xs}-\mathrm{H}]^{-}$, respectively. This pathway must be ruled out because of the specific $44-\mathrm{u}$ loss from the $[\mathrm{Mp}-2 \mathrm{H}]^{2-}$ species. The second possibility is to assume that the loss of $\mathrm{C}_{2} \mathrm{H}_{4} \mathrm{O}$ takes place exclusively after total desolvation of the doubly charged aggregate into $[\mathrm{Mp}-2 \mathrm{H}]^{2-}$. Finally, it is worth noting that for both the MccC7-C51 and the MccC7-C51* molecules, the $\mathrm{CH}_{3} \mathrm{CHO}$ loss did not occur from "in source dissociation".

Product ions generated under low collision energy from deprotonated species. CID experiments of MccC7-C51 were conducted on the molecular $[\mathrm{Mc}-\mathrm{H}]^{-}(\mathrm{m} / \mathrm{z} 1175)$ and $[\mathrm{Mc}-2 \mathrm{H}]^{2-}(\mathrm{m} / \mathrm{z} 587.2)$ species (Figure 4$)$. Note that two common product ions at $\mathrm{m} / \mathrm{z} 445$ and 630 were observed from these two precursor ions. In addition, the CID spectrum of $[\mathrm{Mc}-\mathrm{H}]^{-}$displayed the $m / z 772$ ion corresponding to the $b_{7}^{-}$product ion as base peak, and $\mathrm{a} \mathrm{c}_{6}^{-}$diagnostic ion at $m / z 674$ (Figure $4 \mathrm{a}$ ). The loss 

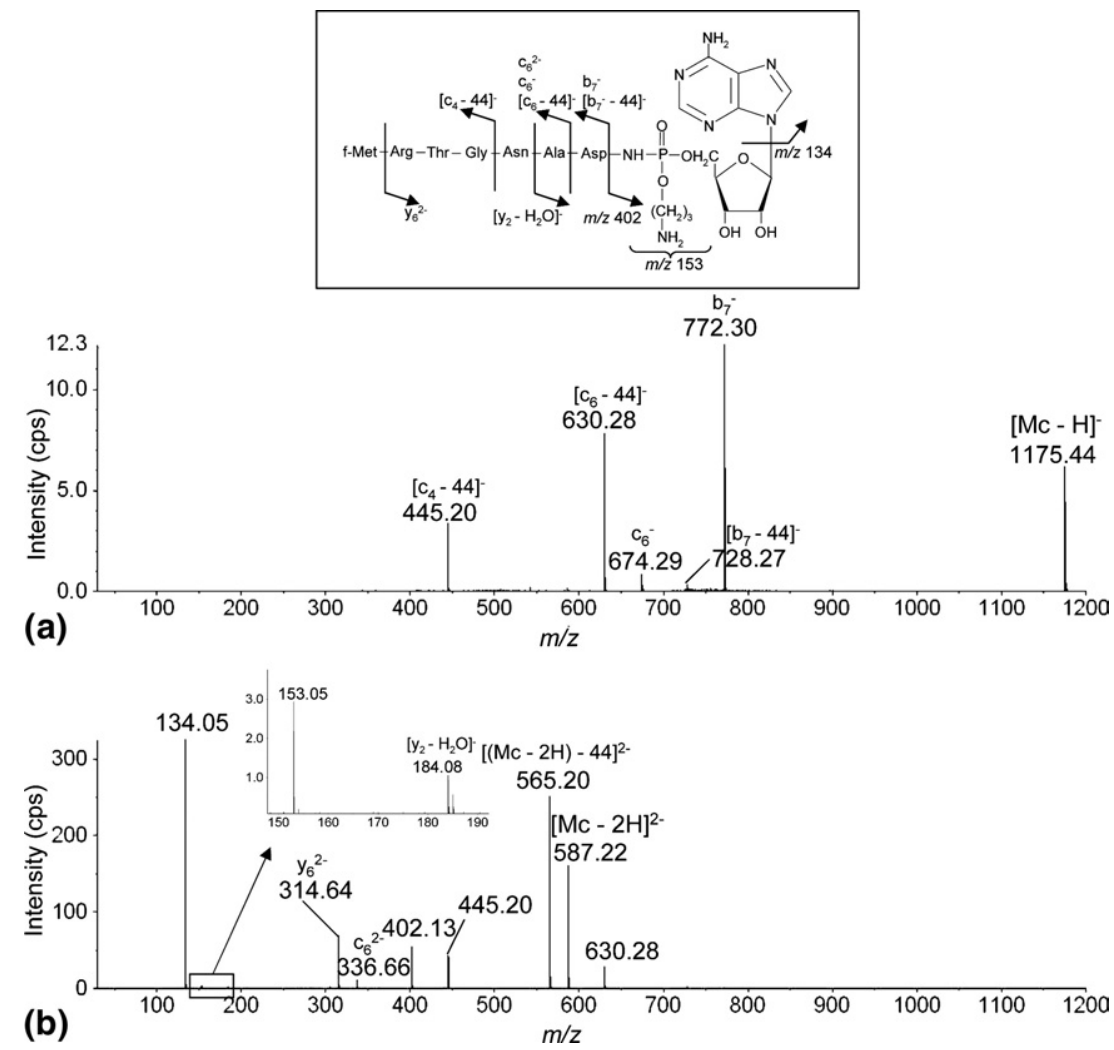

Figure 4. Negative-ion mode CID spectra of MccC7-C51 obtained from $100 \mathrm{pmol} / \mu \mathrm{L}$ solution in 10 $\mathrm{mM}$ ammonium acetate buffer $\mathrm{pH} 6.5$ on the ESI-Qq-TOF instrument. (a) Selection of $[\mathrm{Mc}-\mathrm{H}]^{-}$at $m / z 1175, \mathrm{Ec}=50 \mathrm{eV}$. (b) Selection of $[\mathrm{Mc}-2 \mathrm{H}]^{2-}$ at $m / z 587, \mathrm{Ec}=50 \mathrm{eV}$.

of $44 \mathrm{u}(\mathrm{m} / \mathrm{z} 728)$ from the former was observed, but not directly from $[\mathrm{Mc}-\mathrm{H}]^{-}$in accordance with the "in source" behavior of PepC7-C51. The CID spectrum of the doubly deprotonated $[\mathrm{Mc}-2 \mathrm{H}]^{2-}$ species (Figure $4 b$ ), exhibited the product ion at $m / z 134$ as base peak, which corresponds to the deprotonated adenine species. As observed "in source" for PepC7-C51, a loss of $44 \mathrm{u}\left(\mathrm{CH}_{3} \mathrm{CHO}\right.$ as confirmed by accurate mass measurements) occurred from the $[\mathrm{Mc}-2 \mathrm{H}]^{2-}$ precursor ion, leading to the $m / z 565$ product ion. Several diagnostic ions were also observed at $m / z 184,314$, and 336, which correspond to $\left[\mathrm{y}_{2}-\mathrm{H}_{2} \mathrm{O}\right]^{-}, \mathrm{y}_{6}^{2-}$, and $\mathrm{c}_{6}^{2-}$, respectively. The doubly deprotonated MccC7-C51 species also yielded the $m / z 402$ and 153 product ions, which were attributed to the peptide release and both the peptide and modified nucleotide releases, respectively.

The CID spectrum of the modified aspartyl-adenylate $\left[\mathrm{Mc}^{*}-\mathrm{H}\right]^{-}$species, is shown in Figure 5 . The fragmentation pattern was rationalized by taking into account the formation of ion-dipole complexes (Scheme $5)$, as previously done for the positive-ion mode. In addition to the direct propylamine release ( $d$ pathway) followed by the nucleoside loss $(m / z 175)$, two ion-dipole complexes $\underline{\mathbf{A}}_{1}$ and $\underline{\mathbf{E}}_{1}(\{\mathrm{~m} / \mathrm{z} 134 / 383 \mathrm{u}\}$ and $\{\mathrm{m} / \mathrm{z} 114 / 403 \mathrm{u}\})$ are formed from the precursor [ $\mathrm{Mc}^{*}$ $-\mathrm{H}]^{-}$ion, according to the two distinct $a$ and $e$ pathways:
1. The $\boldsymbol{a}$ pathway, which yields the $\underline{\mathbf{A}}_{1}$ ion-dipole, involves a rearrangement around the phosphate group from the $m / z 382$ ion, leading to the $m / z 250$ product ion and after internal proton transfer, the $\mathrm{m} / z 131$ ion $\left(\underline{\mathbf{A}}_{2}{ }^{\prime \prime}\right.$ ion-dipole) through the $\boldsymbol{a}_{\mathbf{2}}{ }^{\prime}$ process. These consecutive dissociations of $\mathrm{m} / \mathrm{z} 382$ explain the low abundance of this ion compared to its complementary $m / z 134$ product ion.

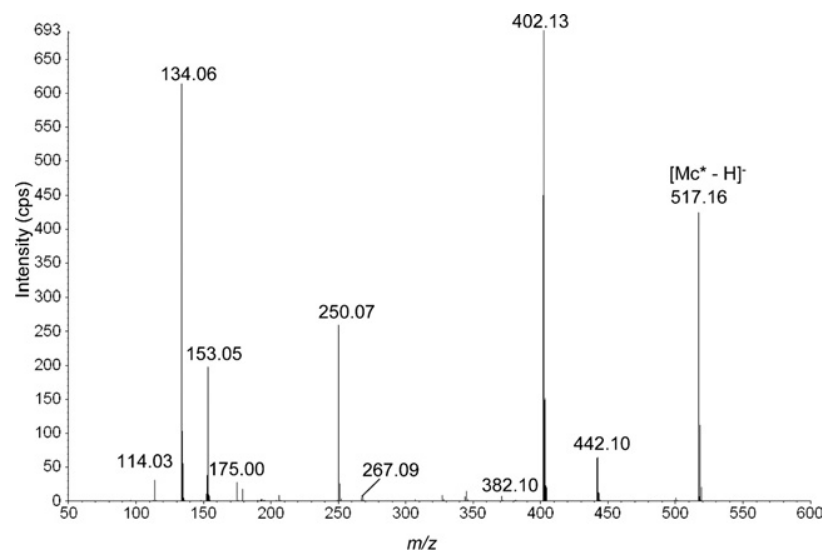

Figure 5. Negative-ion mode CID spectrum of MccC7-C51* $\left(\left[\mathrm{Mc}^{*}-\mathrm{H}\right]^{-}\right.$at $\left.m / z 517\right)$ obtained from $100 \mathrm{pmol} / \mu \mathrm{L}$ solution in 10 $\mathrm{mM}$ ammonium acetate buffer $\mathrm{pH} 6.5$ recorded on the ESI-QqTOF instrument $(\mathrm{Ec}=35 \mathrm{eV})$. 


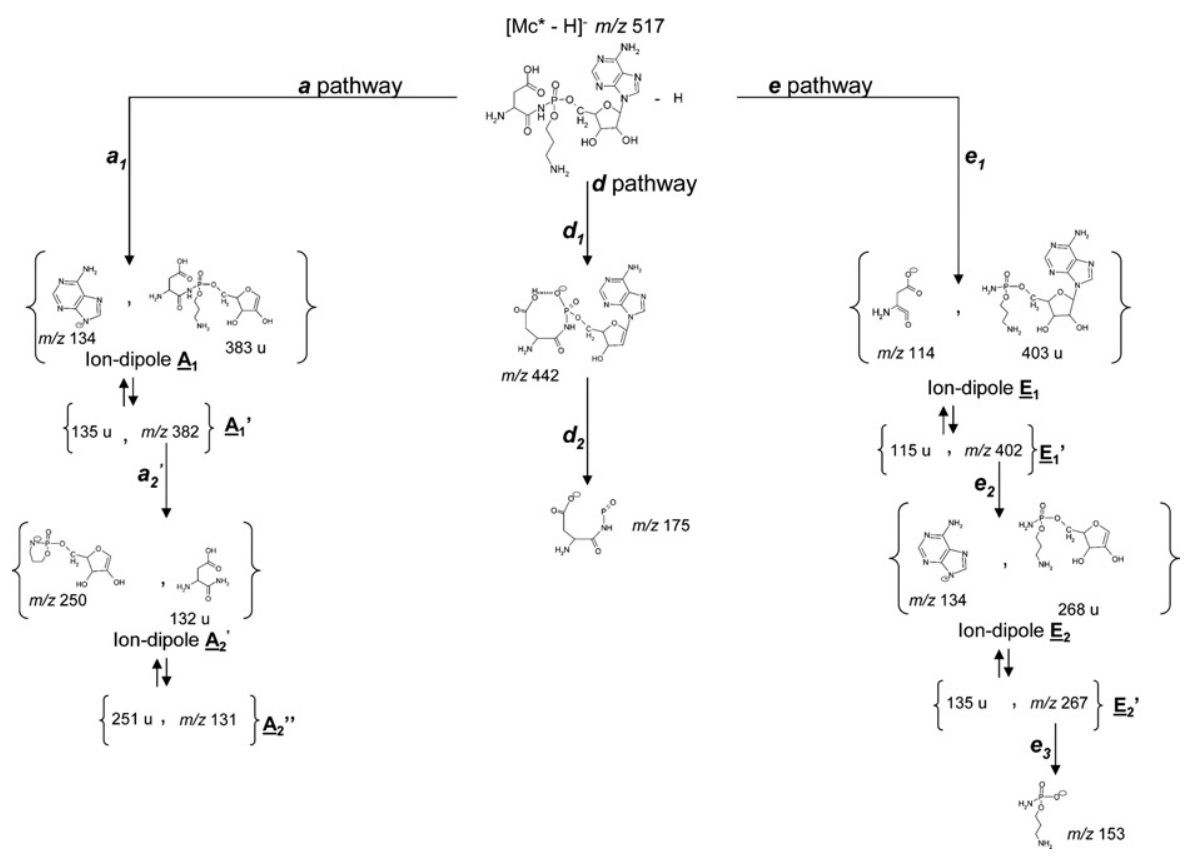

Scheme 5

2. The e pathway leads to the $\underline{\mathbf{E}}_{1}$ ion-dipole $(\{\mathrm{m} / \mathrm{z} 114 /$ $403 \mathrm{u}\})$ through the first step $e_{1}$. The $m / z 402$ ion, which results from aspartic acid release from the precursor ion, appears as the base peak. The adenine release from the $m / z 402$ product ion yields the $\underline{\mathbf{E}}_{2}$ ion-dipole $\{m / z 134 / 268 u\}$ ( $\boldsymbol{e}_{2}$ step). The $m / z 267$ ion can directly lose the ribose group, leading to the $\mathrm{m} / \mathrm{z}$ 153 product ion ( $e_{3}$ step).

The CID spectrum of the deprotonated PepC7-C51 $\left([\mathrm{Mp}-\mathrm{H}]^{-}, m / z\right.$ 789) (Figure 6) showed a base peak corresponding to the $m / z 445$ product ion, together with

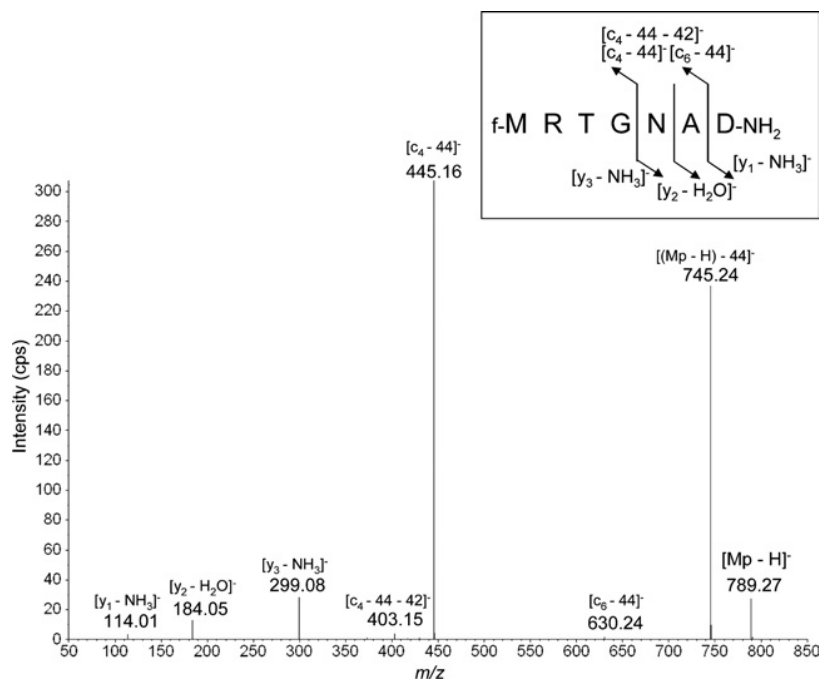

Figure 6. Negative-ion mode CID spectrum of PepC7-C51 $\left([\mathrm{Mp}-\mathrm{H}]^{-}\right.$at $\left.m / z 789\right)$ obtained from $100 \mathrm{pmol} / \mu \mathrm{L}$ solution in 10 $\mathrm{mM}$ ammonium acetate buffer $\mathrm{pH} 6.5$ recorded on the ESI-QqTOF instrument $(\mathrm{Ec}=45 \mathrm{eV})$. several diagnostic ions at $m / z 114,184$, and 299, which were assigned to the $\left[\mathrm{y}_{1}-\mathrm{NH}_{3}\right]^{-},\left[\mathrm{y}_{2}-\mathrm{H}_{2} \mathrm{O}\right]^{-}$, and $\left[\mathrm{y}_{3}-\right.$ $\left.\mathrm{NH}_{3}\right]^{-}$product ions. Those were due to a side-chain cleavage of the aspartic acid and asparagine residues [16]. A loss of $44 \mathrm{u}$ from [Mp $-\mathrm{H}]^{-}$, leading to the $\mathrm{m} / \mathrm{z}$ 745 ion was also observed. Two weak product ions at $m / z 403$ and $m / z 630$ were detected. The former corresponds to a loss of $42 \mathrm{u}$ from the $\mathrm{m} / \mathrm{z} 445$ product ion which can be attributed to a $\mathrm{NH}=\mathrm{C}=\mathrm{NH}$ release from the arginine side chain. This assignment was confirmed by using the LTQ Orbitrap instrument.

Finally, the $\mathrm{m} / \mathrm{z} 445$ and 630 product ions were detected on the CID spectra of both the deprotonated MccC7-C51 and PepC7-C51 molecules. This indicates that these species encompass the peptide part and result from peptide backbone cleavage. To characterize the structure of the $m / z 445$ and 630 product ions, pseudo$\mathrm{MS}^{3}$ and $\mathrm{MS}^{3}$ experiments were performed on both the Qq-TOF and the LTQ Orbitrap instruments. Fragmentation of the selected ion at $\mathrm{m} / \mathrm{z} 630$ triggered the formation of the $\mathrm{m} / \mathrm{z} 445$ ion exclusively. The CID spectrum of the $m / z 445$ ion (data not shown) displayed three major product ions at $m / z 417,403$, and 375 . Formation of these three ions corresponds to a loss of $\mathrm{CO}$ from the formyl group, a loss of $\mathrm{NH}=\mathrm{C}=\mathrm{NH}$ from the arginine residue side chain and consecutive losses of the $\mathrm{CO}$ and $\mathrm{NH}=\mathrm{C}=\mathrm{NH}$ groups, respectively. Finally, an additional analysis of the $m / z 445$ and 630 ions with the LTQ Orbitrap instrument showed that these two ions corresponded to the $\mathrm{c}_{4}^{-}$and $\mathrm{c}_{6}^{-}$diagnostic ions, respectively, both of which underwent a loss of $44 \mathrm{u}$. As discussed previously, this loss resulted from the cleavage of the threonine side chain, as observed upon "in-source" fragmentations of PepC7-C51 (Figure 6). 


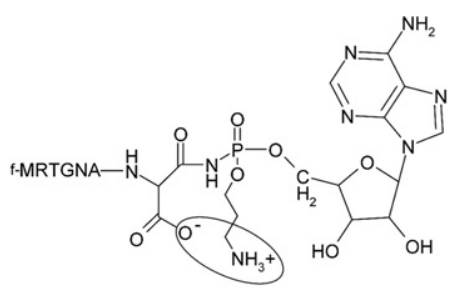

MccC7-C51

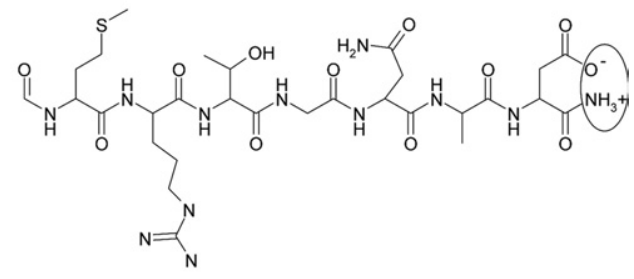

PepC7-C51

Scheme 6

The orientation of the fragmentations towards a loss of $\mathrm{CH}_{3} \mathrm{CHO}$ rather than of $\mathrm{CO}_{2}$ is proposed to result from the formation of a salt bridge. To produce such an electrostatic interaction, zwitterionic forms must be considered. They may occur between the deprotonated aspartate and the protonated amino group of the propylamine chain in the case of MccC7-C51 and between the same aspartate deprotonated site and the protonated amino group at the C-terminus for PepC7-C51 (Scheme 6). In agreement with the proposed zwitterionic structures involving salt bridges, and as expected given the absence of the threonine residue, the CID of the singly charged MccC7-C51* did not lead to any loss of $44 \mathrm{u}$ (Figure 5).

Negative-ion fragmentations of peptides are often as informative as those generated in positive-ion mode [33]. Here, negative-ion mode fragmentations revealed information complementary to those arising from the positive-ion mode, which allowed mainly the characterization of the peptide moiety. The loss of the threonine side chain, which corresponds to a loss of $44 \mathrm{u}$, was favored, while the loss of $\mathrm{CO}_{2}$ from the aspartic acid residue was hindered.

\section{Conclusions}

ESI/MS has been used extensively for the characterization of peptides and biomolecules. Here we show that CID experiments constitute a method of choice to investigate the structure of nucleotide peptides, and that the fragmentation patterns strongly rely on the charge state and charge location. This study shows that both the positive- and negative-ion modes are essential for a complete characterization of such compounds. The complementary studies on PepC7-C51 and MccC7-C51* allowed the interpretation of certain fragmentation pathways of MccC7-C51. The analysis of MccC7-C51 and its two isolated independent regions in positiveand negative-ion modes provided structural information on both the nucleotide and the peptide moieties. Ion-neutral complexes were used to rationalize the fragmentations. Zwitterionic forms appeared to be favored in the gas phase because both basic and acid sites were present [25]. Such zwitterionic species strongly influence the orientation of the fragmentation pathways and, in particular, the hindrance of the $\mathrm{CO}_{2}$ release, which consequently induces the release of the threonine side chain. The mass accuracy provided by the LTQ Orbitrap instrument was a key condition for a comprehensive interpretation of the fragmentation patterns.

\section{Acknowledgments}

The authors thank the mass spectrometry platforms of the Museum national d'Histoire naturelle (MNHN) and the laboratory of Chimie Structurale Organique et Biologique (LCSOB) for access to the ESI-Qq-TOF and LTQ Orbitrap instruments, respectively. The authors are grateful to the MNHN, Université Pierre et Marie Curie (Paris VI) and the Centre National de la Recherche Scientifique (CNRS) for financial support.

\section{References}

1. Jain, A. A.; Rajeswari, M. R. Binding Studies on Peptide-Oligonucleotide Complex: Intercalation of Tryptophan in GC-Rich Region of c-myc Gene. Biochim. Biophys. Acta 2003, 1622, 73-81.

2. Jensen, O. N.; Kulkarni, S.; Aldrich, J. V.; Barofsky, D. F. Characterization of Peptide-Oligonucleotide Heteroconjugates by Mass Spectrometry. Nucleic Acids Res. 1996, 24, 3866-3872.

3. Kuhn-Holsken E.; Lenz, C.; Sander, B.; Lurhrmann, R.; Henning, U. Complete MALDI-TOF MS Analysis of Cross-Linked Peptide-RNA Oligonucleotides Derived from Nonlabeled UV-Irradiated Ribonucleoprotein Particles. RNA 2005, 11, 1915-1930.

4. Lenz, C.; Kuhn-Holsken E.; Henning, U. Detection of Protein-RNA Crosslinks by Nano-LC-ESI-MS/MS Using Precursor Ion Scanning and Multiple Reaction Monitoring (MRM) Experiments. J. Am. Soc. Mass Spectrom. 2007, 11, 869-881.

5. Boschenok, J.; Sheil, M. M. Electrospray Tandem Mass spectrometry of Nucleotide. Mass Spectrom. 1996, 10, 144-149.

6. Lindh, I.; Hjelmqvist, L.; Bergman, T.; Sjovall, J.; Griffiths, W. J. De Novo Sequencing of Proteolytic Peptides by a Combination of C-Terminal Derivation and Nano-Electrospray/Collision-Induced Dissociation Mass Spectrometry. J. Am. Soc. Mass Spectrom. 2000, 11, 673-686.

7. Bowie, J. H.; Brinkworth, C. S.; Dua, S. Collision-Induced Fragmentations of the $(\mathrm{M}-\mathrm{H})$ - Parent Anions of Underivatized Peptides: An Aid to Structure Determination and Some Unusual Negative Ion Cleavages. Mass Spectrom. Rev. 2002, 21, 87-107.

8. Harrison, A. G. Sequence-Specific Fragmentation of Deprotonated Peptides Containing H or Alkyl Side Chains. J. Am. Soc. Mass Spectrom. 2001, 12, 1-13.

9. Chad, C. N.; Microcinloskey, J. A. Collision-Induced Dissociation of Adenine. J. Am. Chem. 1992, 114, 3661-3668.

10. Fu, H. X.; L.Qiang, L.; Wang, J.; Xiao, H.; Zhao, Y. Electrospray Ionization Mass Spectra of Amino Acid Phosphoramidates of Adenosine. Rapid Commun. Mass Spectrom. 2000, 14, 1813-1822.

11. Bowen, R.D.; Williams, D. H. Unimolecular Reactions of Isolated Organic Ions. The Importance of Ion-Dipole Interactions. J. Chem. Soc. Chem. Commun. 1980, 823, 2752-2756.

12. Longevialle, P.; Botter, R. Evidence for Intramolecular Interaction Between Ionic and Neutral Fragments in the Mass Spectrometer. J. Chem. Soc. Chem. Commun. 1980, 17, 823-825.

13. Debrauwer, L.; Rathahao, E.; Jouanin, I.; Paris, A.; Clodic, G.; Molines, H.; Convert, O.; Fournier, F.; Tabet, J. C. Investigation of the Regio- and Stereo-Selectivity of Deoxyguanosine Linkage to Deuterated 2-Hydroxyestradiol by Using Liquid Chromatography/ESI-Ion Trap Mass Spectrometry. J. Am. Soc. Mass Spectrom. 2003, 14, 364-372.

14. Cole, R. B.; Tabet, J. C.; Salles, C.; Jallageas, J. C.; Crouzet, J. Structural "memory effects" influencing decompositions of glucose alkoxide anions produced from monoterpene glycoside isomers in tandem mass spectrometry. Rapid Commun. Mass Spectrom. 1989, 3, 59-61. 
15. Bowie, J. H. The Fragmentations of Even-Electron Organic Negative Ions. Mass Spectrom. Rev. 1990, 9, 349-379.

16. Duquesne, S.; Destoumieux-Garzon, D.; Peduzzi, J.; Rebuffat, S. Microcins, Gene-Encoded Antibacterial Peptides from Enterobacteria. Nat. Prod. Rep. 2007, DOI:10.1039/paper no B516237H.

17. Guijarro, J. I.; Gonzalez-Pastor, J. E.; Baleux, F.; San Millan, J. L.; Castilla M. A.; Rico, M.; Moreno, F.; Delepierre, M. Chemical Structure and Translation Inhibition Studies of the Antibiotic Microcin C7. J. Biol. Chem. 1995, 270, 23520-23532.

18. Metlitskaya, A.; Kazakov, T.; Kommer, A.; Pavlova, O.; Praetorius-Ibba, M.; Ibba, M.; Krasheninnikov, I.; Kolb, V.; Khmel, I.; Severinov, K. Aspartyl-tRNA Synthetase is the Target of Peptide Nucleotide Antibiotic Microcin C. J. Biol. Chem. 2006, 281, 18033-18042.

19. Duquesne, S.; Petit, V.; Peduzzi, J.; Rebuffat, S. Structural and Functional Diversity of Microcins, Gene Encoded Antibacterial Peptide from Enterobacteriaceae. J. Mol. Microbiol. Biotechnol. 2007, 13, 200-209.

20. Makarov, A. Electrostatic Axially Harmonic Orbital Trapping: A highPerformance Technique of Mass Analysis. Anal. Chem. 2000, 72, 11561162.

21. Hardman, M.; Makarov, A. A. Interfacing the Orbitrap Mass Analyzer to an Electrospray Ion Source. Anal. Chem. 2003, 75, 1699-1705.

22. Hu, Q.; Noll, R. J.; Li, H.; Makarov, A.; Hardman, M.; Graham Cooks, R The Orbitrap: A New Mass Spectrometer. J. Mass Spectrom. 2005, 40, $430-443$.

23. Makarov, A. D.; E.Lange, O.; Horning, S. Dynamic Range of Mass Accuracy in LTQ Orbitrap Hybrid Mass Spectrometer. J. Am. Soc. Mass Spectrom. 2006, 17, 977-982.

24. Peterman, S. M.; Duczak, N., Jr.; Kalgutkar, A. S.; Lame, M. E.; Soglia, J. R. Application of a Linear Ion Trap/Orbitrap Mass Spectrometer in Metabolite Characterization Studies: Examination of the Human Liver Microsomal Metabolism of the Nontricyclic Antidepressant Nefaz- odone Using Data-Dependent Accurate Mass Measurements. J. Am. Soc. Mass Spectrom. 2006, 17, 363-375.

25. Nordhoff, E. K.; F; .Roepstorff, P. Mass Spectrometry of Nucleic Acids. Mass Spectrom. Rev. 1996, 15, 67-138.

26. Fournier, F.; Remaud, B.; Blasco, T.; Tabet, J. C. Ion-dipole Complex Formation from Deprotonated Phenol Fatty Acid Esters Evidenced by Using Gas-Phase Labeling Combined with Tandem Mass Spectrometry. J. Am. Soc. Mass Spectrom. 1993, 4, 343-351.

27. Madalinski, G.; Fournier, F.; Wind, F. L.; Afonso, C.; Tabet, J. C. Gram-Negative Bacterial Lipid A Analysis by Negative Electrospray Ion Trap Mass Spectrometry: Stepwise Dissociations of Deprotonated Species Under Low Energy CID Conditions. Int. J. Mass Sepctrom. 2006, 249/250, 77-92.

28. Sleno, L.; Volmer, D. A. Ion Activation Methods for Tandem Mass Spectrometry. J. Mass Spectrom. 2004, 39, 1091-1112.

29. Roepstorff, P.; Fohlman, J. Proposal for a Common Nomenclature for Sequence Ions in Mass Spectra of Peptides. Biomed. Mass Spectrom. 1984, 11,601 .

30. Biemann, K. Appendix 5. Nomenclature for Peptide Fragment Ions (Positive Ions). Methods Enzymol. 1990, 886-887.

31. Bunk, D. M.; Macfarlane, R. D. Fragmentation of Proteins in the 13- to 29-kDa Mass Range Observed by 252Cf-Plasma Desorption Mass Spectrometry. Proc. Natl. Acad. Sci. U.S.A. 1992, 89, 6215-6219.

32. Dongré, A. R.; Jones, J. L.; Somogyi, A.; Wysocki, V. H. Influence of Peptide Composition, Gas-Phase Basicity, and Chemical Modification on Fragmentation Efficiency: Evidence for the Mobile Proton Model. J. Am. Chem. Soc. 1996, 118, 8365-8374.

33. Steinborner, S. T.; Bowie, J. H. The Negative Ion Mass Spectra of [M $\mathrm{H}]-$ Ions Derived from Caeridin and Dynastin Peptides. Internal Backbone Cleavages Directed through Asp and Asn Residues. Rapid Commun. Mass Spectrom. 1997, 11, 253-258. 